\title{
La tradición en la hermenéutica de Hans Georg Gadamer
}

\author{
María Teresa Douzet ${ }^{1}$
}

Trabajo recepcionado: junio 2007

Trabajo aceptado: julio 2007

\section{RESUMEN}

Este trabajo presenta la hermenéutica gadameriana que concibe la historia como flujo inagotable de verdades que se desprende del diálogo entre el intérprete y la obra. Aquello por conocer no es el pasado en si mismo, sino lo que fue en relación a lo que es. Las verdades acontecen a partir de la mediación entre pasado y presente. Tal mediación es realizada por la tradición. Desde, hacia y en la tradición es posible la Verstehen, la comprensión.

PALABRAS CLAVE: hermenéutica, comprensión, interpretación, tradición

\begin{abstract}
This work presents Gadamer's hermeneutics which conceives history as an inexhaustible flow of truths emerging from the dialogue between the interpreter and the piece of work. What is left to know is not the past itself, but what it was in relation to what it is. The truths occur in the mediation between past and present. Such mediation is done by tradition. To, from and within tradition Verstehen, comprehension, is possible.
\end{abstract}

KEY WORDS: hermeneutics, comprehension, interpretation, tradition

1 Socióloga, Doctora en Historia@, Pontificia Universidad Católica de Chile. 
El filósofo alemán Hans Georg Gadamer $(1900-2003)^{2}$ da un giro en la forma de concebir la hermenéutica. No la ve como método o técnica de interpretación que entiende el conocimiento como el resultado deliberado de un sujeto autónomo, sino como un acto de conocer, como un evento en su naturaleza episódica y transubjetiva. Episódica, porque es un momento en la vida de la tradición donde autor e intérprete aparecen como momentos subordinados. Transubjetiva, porque lo que ocurre es una mediación transformadora que acontece más allá del control de quien conoce. ${ }^{3}$ Entender esta mediación es entender y participar de aquello que la tradición nos quiere decir. Ciertamente, la tradición ocupa en la teoría gadameriana un lugar privilegiado. El autor la revitaliza y reposiciona al interior de la discusión filosófica contemporánea. El rescate de la tradición realizada por Gadamer es una reacción a los avances de la llustración y del método científico que patrocina. Este filósofo se distancia de uno de los principios básicos ilustrados: el rechazo a la tradición por ser un "juicio sin fundamento" que escapa a los criterios de certeza dados por el racionalismo cartesiano.

Kant establece claramente los principios de la Ilustración al afirmar que sólo el sujeto puede constituir un juicio. Debe seguir su propio entendimiento y dejar de lado lo que no calce en los criterios de la razón. Solo así es posible superar la "minoría de edad". Para el mundo ilustrado la tradición es tal minoría de edad porque es prejuiciosa. Sin embargo, Gadamer hace ver que la propia llustración se constituye en aquello que critica. Ella misma es prejuiciosa. Ha promulgado y transmitido desde Descartes que solo un sujeto autosuficiente y autoconsciente que ignora su propia temporalidad y el carácter histórico de la interpretación puede alcanzar el ideal del conocimiento. ${ }^{4}$ El prejuicio básico de la Ilustración es el prejuicio contra todo prejuicio. El efecto de este principio que discrimina lo que no es racional termina, a juicio del autor, por desvirtuar y desvalorizar la tradición ${ }^{5}$. Contra esta visión subjetivista se posiciona la hermenéutica gadameriana.

El contraste entre el mundo ilustrado y Gadamer es evidente. Mientras la llustración es quiebre con la tradición por considerarla absurda e imposible, la hermenéutica gadameriana es continuidad. Mientras para la mirada ilustrada la tradición solo es explicable como obj eto histórico que perdido en el pasado ha permanecido inmóvil, para la óptica gadameriana la tradición es flujo acontecido que no cabe dentro de la categoría de objeto porque no es algo externo y ajeno a ser aprehendido reflexivamente. Mientras la Ilustración opone tradición y razón -la primera es opresión que atenta contra la libertad a la cual aspira todo ser racional-, Gadamer la entiende como momento de libertad que requiere de la razón para conservarse.

En realidad la tradición siempre es también un momento de la libertad y de la historia. Aun la tradición más auténtica y venerable no se realiza, naturalmente, en virtud de la capacidad de permanencia de lo que de algún modo ya está dado, sino que necesita ser afirmada, asumida y cultivada. La tradición es esencial mente conservación, y como tal nunca deja de estar presente en los cambios históricos. Sin embargo, la conservación es un acto de la razón,

2 Gadamer nace en 1900 en la ciudad de Marburgo. En 1918 inicia sus estudios en la Universidad de Breslau para luego trasladarse a la Universidad de Marburgo donde la crítica al "metodologismo" de la Escuela Neokantiana, a la teología histórica, a los trabajos de Wilhelm Dilthey, Ernst Troeltsh, Stefan Georg, pero en particular de Friedrich Nietzsche conforman el núcleo del debate académico. Después de dos años en la Universidad de Frankfurt, en 1949, es Ilamado a la Universidad de Heidelberg en reemplazo de Karl J aspers. En esta casa de estudios -donde es nombrado profesor emérito (1968)- prepara su gran obra Verdad y Método (1960). En los años posteriores Gadamer realiza clases en diversas universidades europeas y norteamericanas. Dentro de su gran producción, vale destacar algunos de sus trabajos: El problema de la conciencia histórica (1958), La razón en la edad de la ciencia (1981), La actualidad de lo bello (1986), La ética de la dialéctica de Platón (1991), Los caminos de Heidegger (1994), El inicio de la filosofía occidental (1998) y un conjunto de artículos compilados en Kleine Schriften (1967) y en Verdad y Método, Tomo II (1986). Muere en marzo de 2003. Ver Gadamer, Hans Georg, "Reflections on my Philosophical J ourney" (pp. 3-57), en Edwin, Lewis, The Philosophy of Hans Georg Gadamer. Chicago and La Salle, USA, 1997.

3 Linge, David. (ed.) "Editor's Introduction", en Gadamer, Hans Georg. Philosophical Hermeneutics, University of California Press, USA, p. 1977, p. XXVIII.

4 Ibid., p. XVI.

5 Gadamer, Hans Georg (1997), Verdad y Método, Ediciones Sígueme, séptima edición (primera 1960), Salamanca, p. 337. 
aunque caracterizado por el hecho de no atraer la atención sobre sí. ${ }^{6}$

\section{Conservación, transformación e} innovación son conductas libres dentro de la teoría gadameriana. Este argumento no puede entenderse desde un concepto de tradición como limitación del conocimiento, sino como su posibilidad al interior de las Geisteswissenschaften, de las ciencias del espíritu.

La noción de tradición de Gadamer no se reduce a un conjunto de normas, creencias e instituciones transmitidas y respetadas de generación en generación, ${ }^{7}$ no es un ámbito recóndito al cual se acuda en un desesperado salto temporal romántico por aprehender un pasado lejano y nostálgico, ni tampoco un obstáculo a remover por no estar vestida con los ropajes de la razón ilustrada. La palabra germana Über-lieferung que significa transmisión (siempre que alguien esté dispuesto a recibir lo transmitido) es clave para aproximarse a la idea de tradición gadameriana. La aceptación y participación de la tradición no es pasiva. ${ }^{8}$ Es un traspaso del cual se participa activamente; se es parte de aquello que se está recibiendo. La tradición es un proceso donde algo acontece y se actualiza cada vez que lo comprendemos, es decir, cada vez que participamos de ella. La tradición es un flujo en el cual nos formamos. Como heredero de esta visión, Gadamer puede afirmar que:
En nuestro comportamiento respecto al pasado, que estamos confirmando constantemente, la actitud real no es la distancia ni la libertad respecto a lo transmitido. Por el contrario nos encontramos siempre en tradiciones, y este nuestro estar dentro de ellas no es un comportamiento objetivador que pensara sobre algo extraño o ajeno lo que dice la tradición; esta es siempre más bien algo propio, ejemplar 0 aborrecible, es un reconocerse en el que para nuestro juicio histórico posterior no se aprecia apenas conocimiento, sino un imperceptible ir transformándose al paso de la misma tradición. ${ }^{9}$

La relación con la tradición es experiencial, no reflexiva. La tradición no es un obj eto a ser aprehendido desde una conciencia independiente y diferenciada. La comprensión de la tradición dentro de la hermenéutica de Gadamer se sustrae de la oposición epistemológica sujeto/objeto promulgada por la filosofía moderna, y en especial por la kantiana. Quien se sumerge en la tradición para comprenderla es un ser finito, un Dasein. Arrojado en el mundo interpreta dentro de sus posibilidades, dentro de su apertura y finitud el conjunto de voces nunca acabadas del pasado. ${ }^{10}$ Intérprete y obra se fusionan en el círculo hermenéutico; son parte de un mismo movimiento comprensivo-interpretativo. La comprensión es el encuentro de estas dos finitudes insertas cada una en su respectiva

6 Pp. cit., p. 349.

7 Esta es la más clásica y difundida definición dada al concepto de tradición. Ver Abbagnano, Nicola (1966) Diccionario de filosofía, Fondo de Cultura Económica, México, p. 1146 y Ferrater, José (1988), Diccionario de filosofía, Tomo 4. Alianza Editorial, Sexta reimprensión, España, p. 3296

8 Martin Heidegger (1889-1976), referente directo de Gadamer, utiliza esta palabra para aludir a la herencia activa del pasado como posibilidad abierta, no como esquema rígido y determinante. A la luz de lo anterior, Heidegger habla de una "constitución" crítica de la tradición donde las posibilidades heredadas son reconocidas en su finitud (historicidad, contingencia, multiplicidad) y convertidas en objeto de elección. Vattimo, Gianni (1992), Ética de la interpretación, Ediciones Paidós, Argentina, p. 180.

9 Gadamer, op. cit., p. 350.

10 La noción de finitud ontológica y gnoseológica del hombre puede comprenderse a partir del gran aporte heideggeriano, a saber la conjunción del problema del ser con el problema de la existencia y que toma cuerpo en el concepto de Dasein. Las ideas planteadas en la gran obra de Heidegger Ser y tiempo (1927) son una crítica a la filosofía de principios del siglo XX por haber olvidado la real esencia del ser al comprenderlo sólo como presencia. El "estar ahí" -el hombre- no es sólo un ente que se plantea la pregunta sobre el sentido del ser. El hombre es también el ente que no se deja reducir a la noción de ser. Heidegger rechaza la identificación ser-objetividad que realiza la filosofía occidental, es decir, la identificación del ser con la simple presencia. El "estar ahí" es aque ente para el cual las cosas están presentes, por lo tanto, él mismo no es reducible a la mera presencia. El concepto del ser como algo que subsiste, que se da y que en estos términos es considerado como objetivo es lo que lleva a Heidegger a reexaminar y a replantear el problema del ser, argumentando que de la manera hasta entonces vista no es posible concebir la historicidad y la vida en su efectividad. Reale, Giovanni y Antiseri, Darío. Historia del pensamiento filosófico y científico, Tomo tercero, Editorial Herder, Barcelona, 1988, p. 518, pp. 518-519. 
situación hermenéutica, es decir, en su propio horizonte. Lo que se ofrece a la comprensión en el texto es un momento particular de la tradición en su historicidad, no es toda la tradición. Quien comprende este momento es un ser también finito. La comprensión es movimiento que va de una finitud a otra finitud, pero no por ello la propia comprensión es finita. Al contrario, la comprensión de una obra es un proceso inagotable porque ella misma es fuente permanente de sentido que se mantiene mientras alguien interprete. De esta comprensión como rasgo ontológico y fenómeno lingüístico, de sus características, alcances y limitaciones trata la obra magistral de Gadamer Verdad y Método, escrita en 1960. Sus más de seiscientas páginas albergan el gran legado del autor al debate filosófico de los últimos cuarenta años.

¿De qué manera la tradición articula y posibilita la comprensión? ¿Qué implicancias tiene esta concepción gadameriana de la tradición en la interpretación histórica? A la luz de estas interrogantes, los objetivos de este trabajo son: discutir el espacio y papel que juega la tradición en el proceso comprensivo del "ser en el mundo"; y analizar los alcances y limitaciones de la tradición gadameriana.

\section{Círculo hermenéutico gadameriano}

La hermenéutica refiere al problema de la comprensión y de la correcta interpretación de textos. Asume como punto de partida la articulación de sentido entre el todo y las partes al interior de un círculo comprensivo. Se comprende el todo desde lo individual y lo individual desde el todo. El sentido del texto se obtiene en relación a su contexto general y el contexto es, a su vez, comprendido desde la obra particular. Si no hay congruencia, la comprensión fracasa. ${ }^{11}$ Así como señala Emerich Coreth, la estructura de comprensión hermenéutica es circular porque la intelección ${ }^{12}$ de un contenido singular está condicionada por una totalidad precomprendida. ${ }^{13}$

De esta mediación en la cual el presente aprende del pasado, se desprende la verdad. La diferencia con el pasado -que puede separar al intérprete de la obra- no es obstáculo para su entendimiento, sino su condición. ${ }^{14}$ La comprensión es en sí misma un momento de la tradición, es episódica. Por consiguiente, la aprehensión del pasado como momento del presente no es reproducción sino producción; no es inmediatez, sino mediación. Lo "clásico", aquello que por su dominio histórico y validez se mantiene frente a la crítica histórica, sirve a Gadamer como modelo para explicar esta mediación. Lo clásico sigue hablándole al presente, no es algo que desapareció y que solo sea accesible superando la distancia histórica. ${ }^{15}$ Para el autor lo clásico es intemporal porque es lo permanente, lo imperecedero. Su significado es independiente de la circunstancia temporal. Es por lo tanto, la pervivencia de la elocuencia de una obra fundamentalmente ilimitada que se sigue interpretando.

Como podemos observar, la noción de distancia temporal no es vacía, tiene un contenido positivo porque es expresión de la tradición acontecida en cada momento de interpretación. Ajuicio de Gadamer, la distancia en el tiempo no es una brecha a superar para poder comprender el pasado. En este sentido, el autor rompe con la concepción historicista que promueve la necesidad de salvar el abismo temporal para poder desplazarse al espíritu de la época, pensando en sus conceptos y

11 Gadamer, op, cit., p. 361

12 Coreth utiliza el concepto de intelección en los términos que lo hace Gustav Droysen (1808-1884) quien lo distingue del concepto de esclarecimiento. "Esclarecimiento significa el retrotraer causalmente el fenómeno aislado a la ley general y necesaria; intelección, por el contrario, la concepción de lo singular en su peculiaridad y en su significación.", en Coreth, Emerich (1972), Cuestiones fundamentales de hermenéutica, Editorial Herder, Barcelona, p. 33.

13 Cabe destacar que desde los trabajos del teólogo protestante alemán Friedrich Schleiermacher (1769-1834) y, en particular, desde la obra del historiador germano Droysen la hermenéutica empieza a adquirir un carácter comprensivo circular. Ibid., p. 35. 14 Weinsheimer, Joel C. (1985), Gadamer's Hermeneutics: a reading of Truth and Method. Yale University Press, New York, pp. 133-134.

15 Gadamer, op. cit., pp. 356-359. 
representaciones. Al contrario, la distancia temporal tiene una connotación positiva y productiva porque en ella se expresa la continuidad de la tradición y porque en ella se juega la comprensión. ${ }^{16}$ Fruto de esta mediación temporal la comprensión acontece, la interpretación de la tradición fluye. La interpretación hace explícita la comprensión en la medida que se introduce en aquello que comprende. ${ }^{17}$

Comprensión e interpretación son parte del mismo proceso, por ello se puede hablar tanto de una interpretación comprensiva como de una comprensión interpretativa. No se puede hacer una distinción entre qué se dice y cómo se dice porque conforman una unidad. La interpretación tiene siempre algo de accidental porque, en definitiva, la comprensión es siempre un acontecer, un fluir. Con todo, la historia no es un conjunto de eventos a ser explicados de manera fija y estática, sino un conocimiento dinámico que se sustenta en la compenetración pasada y presente, es decir, en la mediación que no es sino la propia forma de ser histórico y que no es reducible, por lo tanto, a la subjetividad del historiador. ${ }^{18}$

Ahora bien, Gadamer busca comprender la tradición. Comprenderla implica ponerse de acuerdo en ella, es decir, en lo que quiere decir. La tradición como "pluralidad de voces" habla; es lingüisticidad. Por lo tanto, el tema no es llegar a la intención del autor ni acceder a su subjetividad como lo pretendiera el romanticismo y la hermenéutica de Friedrich Schliermacher (1769-1834) y de Wilhelm Dilthey (1833-1911), sino comprender la cosa en sí. Gadamer reacciona contra la alienación de la historicidad que caracteriza las posturas de Schleiermacher y Dilthey porque aún rinden tributo a los principios cartesianos e ilustrados. Sólo un sujeto trascendental puede pensar en liberarse de su historicidad para superar la distancia histórica y así introducirse en la intencionalidad de otro. Tal intento implica no asumir que el presente es una extensión vital del pasado. ${ }^{19}$ Para Gadamer es imposible acceder a la intentio autoris. Tal búsqueda de reproducción del pasado no tiene sentido. En su opinión es erróneo fundar la compresión en una "congenialidad" que aúne a autor e intérprete. No es necesario para entender el sentido de la tradición. Por lo tanto, no es relevante para las ciencias del espíritu. La hermenéutica gadameriana como movimiento circular no tiene un punto inicial ni un punto final. Lo central no es el autor como inaugurador del sentido, ni el público como recepcionista de la obra, lo que importa es la obra en sí misma. ${ }^{20}$

Por consiguiente, para Gadamer los intentos del historicismo por reconstruir el pasado pecan de ingenuos. La comprensión no es un acto de reproducción, sino de producción: el texto interpretado cuenta sus verdades y con ello gatilla el diálogo donde aflora la tradición. El texto es siempre exceso de sentido. En este proceso comprensivo la tradición habla y el intérprete escucha, pregunta y vuelve a preguntar. Dado que la comprensión es transubjetiva, en este diálogo ambos se transforman porque algo nuevo emerge. ${ }^{21}$ En la medida que el intérprete escucha y se deja decir por lo transmitido, es interpelado por la tradición. De esta manera pasa a ser parte de aquello que acontece, es decir, de la comunicación lingüística que se da entre el presente y el pasado y que hace su camino en toda comprensión. Algo acontece, eso es lo decisivo. No podría ser de otra manera porque el intérprete en tanto Dasein está implicado en el mundo. Al interpretar transforma el texto y se transforma a sí mismo; el mundo se transforma tras cada proceso interpretativo. Como expresión de la tradición, el texto siempre está abierto a nuevas interpretaciones. Cada una de ellas va dando cuerpo a lo que Gadamer Ilama

16 Ibid., p. 367.

17 Ibid., p. 478.

18 Weinsheimer, op. cit., p. 175

19 Linge, op. cit., p. XIV.

20 Gadamer, op. cit., p. 366

21 Ibid., p. 553. 
Wirkungsgeschiche, "historia de los efectos", 22 inevitable una vez que se asume la distancia temporal. El proceso histórico se transforma en la medida que los efectos se suceden y padecen. El interés histórico no solo recae sobre los fenómenos o las obras, sino también sobre los efectos de la misma historia. La historia efectual es la historia de estos efectos que son parte del propio comprender. No es algo que se agregue al texto, está en el propio organismo de la comprensión. La interpretación no puede desligarse del impacto, de la repercusión y de las distintas interpretaciones que ha tenido la obra a lo largo del tiempo y que trascienden, por cierto, los motivos e intenciones originales del autor. La "historia de los efectos" revela que no hay inmediatez en el proceso del comprender, sino mediación y apertura. Es un concepto que da cuenta de la comprensión como un proceso inacabado, dinámico y productor de sentido. Cada nueva comprensión implica una conversación diferente porque surgen nuevos decires, nuevas escuchas, nuevas preguntas que se van acumulando tras las sucesivas interpretaciones a lo largo del tiempo. En consecuencia, no es posible hablar de una interpretación correcta, única ni final que dé cuenta del sentido acabado de la obra porque ésta es siempre abundancia de significado. La obra es fuente infinita de sentido y de verdades.

\section{El valor de la tradición}

El círculo hermenéutico se conforma, entonces, entre una tradición que Ilama a ser comprendida y un intérprete, un Dasein que está dispuesto a hacerlo. ${ }^{23}$

El círculo no es, pues, de naturaleza formal; no es subjetivo ni objetivo, sino que describe la comprensión como la interpenetración del movimiento de la tradición y del movimiento del intérprete. La anticipación de sentido que guía nuestra comprensión de un texto no es un acto de la subjetividad sino que se determina desde la comunidad que nos une a la tradición. Pero en nuestra relación con la tradición, esta comunidad está sometida a un proceso de continua formación. No es simplemente un presupuesto bajo el que nos encontramos siempre, sino que nosotros mismos la instauramos en cuanto que comprendemos, participamos del acontecer de la tradición y continuamos determi nándolo así desde nosotros mismos. El círculo de la comprensión no es en este sentido un círculo "metodológico" sino que describe un momento estructural ontológico de la comprensión. ${ }^{24}$

Esta circularidad revela que la comprensión es posible porque algo de la tradición interpela al intérprete, lo invita. Éste acude porque tiene un vínculo con quien lo ha invitado, porque existe una unidad previa. Existe una preestructura lingüística en común, una "comunidad de prejuicios fundamentales y sustentadores" que permite anticipar y darle sentido a la comprensión. ${ }^{25}$

Tres son las relaciones que articulan, en definitiva, la compenetración interpretativa histórica: formación-comprensión, lenguajecomprensión y prejuicio-comprensión. Las tres están estrechamente vinculadas porque obra e intérprete están formados en prejuicios, en precomprensiones que no son sino expresiones y estructuras lingüísticas. Se comprende desde y hacia tradiciones cargadas de formas de conocer y aprehender el mundo. La comprensión es, por consiguiente, prejuiciosa. De lo anterior se desprende una de las ideas claves en la filosofía de Gadamer: la tradición es el

22 Ibid., p. 371.

23 La comprensión, desde la analítica existencial heideggeriana, es un rasgo ontológico que da cuerpo a un círculo también ontológico. Ésta es la novedad filosófica retomada por Gadamer. El autor no asume la comprensión como modo de comportamiento, sino como rasgo propio del "estar ahí". Bajo este principio la hermenéutica gadameriana designa el carácter finito y específico de quien comprende, es decir, el carácter fundamentalmente móvil del "estar ahí". Gadamer, op. cit., pp., 11-12.

24 Gadamer, op. cit., p. 363.

25 Ibid., p. 365. 
criterio, el marco de comprensión, pero no en términos de restricción, sino de contención: la tradición contiene la comprensión. A diferencia del planteamiento ilustrado, la tesis gadameriana sostiene que el mundo de las tradiciones no es un obstáculo a remover que limite la comprensión. Por el contrario, la posibilita y condiciona. En dicha articulación acontecen las verdades. ${ }^{26}$

Formación-comprensión

$$
\text { El concepto alemán Bildung, }
$$
traducido al español como "formación", permite acercarse a la centralidad que tiene en Gadamer la tradición como articuladora de unidad, de sentido y de verdades. Brevemente, Bildung es tanto el proceso por el cual se adquiere cultura como el resultado de la formación de los contenidos de una tradición ${ }^{27}$. Pero el vocablo encierra una riqueza mayor, directamente relacionado con el concepto de Über-lieferung que ilumina sobre el profundo significado que tiene la tradición en la filosofía gadameriana. Sus palabras al respecto son elocuentes:

(...) en la formación uno se apropia por entero de aquello en lo cual y a través de lo cual uno se forma. En esta medida todo lo que ella incorpora se integra en ella, pero lo incorporado en la formación no es como un medio que haya perdido su función. En la formación alcanzada nada desaparece, sino que todo se guarda. Formación es un concepto genuinamente histórico, y precisamente de este carácter histórico de la "conservación" es de lo que se trata en la comprensión de las ciencias del espíritu. ${ }^{28}$

La noción de formación va más allá de la mera apropiación de una idea transmitida.
Refiere a una apropiación activa de lo que nos forma y de lo que a su vez pasamos a integrar. Formarse es seguir haciendo propia la tradición, es seguir participando de ella. Formación implica, entonces, continuidad con el torrente de la tradición que no deja de decirnos cosas.

Ahora bien, los conceptos de formación y de comprensión están íntimamente relacionados en la hermenéutica de Hans Georg Gadamer. La esencia de la formación es convertirse en un ser espiritual general y no abandonarse a la propia particularidad. Exige de sacrificios, concretamente, la inhibición del deseo y, con ello, la restricción de la libertad. En la medida que el hombre se forma gana "poder", habilidades, destrezas, hábitos con lo cual adquiere conciencia de sí mismo y de esa manera logra superar su inmediatez hacia la generalidad para desde allí comprender lo otro. Lo otro en Gadamer no tiene el carácter que el mundo ilustrado le da a la alteridad como pura extrañeza y diferenciación. Como veremos a continuación, la tradición tiene un poder vinculante, por lo tanto, la alteridad es posible indiferenciación y eventual pertenencia. Mientras las posturas modernistas rompen con lo extraño, con lo que no calza dentro de patrones racionales, y mientras la mirada más clasicista pretende supeditar la diferencia bajo criterios dados, conocidos e impositivos, Gadamer dialoga con la extrañeza, a través de la tradición. No la evita, ni la domina. ${ }^{29}$

La formación permite la apertura, fundamental para iniciar el movimiento de interpretación hacia el otro. En este desplazamiento receptivo hacia la alteridad, el Dasein no se aparta de sí, sino se lleva a sí mismo en una actitud de diálogo. La idea no es comprender al otro, sino comprender lo que dice. ${ }^{30}$ El saber hermenéutico no es apropiación con carácter de conquista, no es un "saber dominador"; es disposición y apertura. ${ }^{31}$ Como 
no busca introducirse en la subjetividad del otro, es posible ser consciente de la alteridad, individualidad, irreductibilidad y concreción histórica. Así, el intérprete gana un horizonte. ${ }^{32}$ Gadamer entiende por horizonte el ámbito de lo visible desde un determinado punto porque no es posible abarcarlo todo ni ser consciente de todo. Pero esta inabarcabilidad no es un defecto, sino la esencia misma del ser histórico que nunca se acaba. ${ }^{33}$ La "historia de los efectos" no requiere ser reconocida para que exista; los efectos se suceden aún cuando no tengamos conciencia de su devenir. La conciencia de la historia efectual no sigue el modelo del sujeto trascendental como conciencia infinita e ilimitada. Es, más bien, conciencia del horizonte al interior del cual está situado el Dasein.

La elaboración y conciencia de una situación hermenéutica pasa, entonces, por situarse como Dasein y por situar al otro también como un ente arrojado en el mundo para así reconocerlo y comprenderlo. En el proceso interpretativo hay unidad entre lo interpretado y quien interpreta, pero esa unidad rescata la particularidad y finitud de cada cual, es decir, su horizonte. De esta manera es posible el movimiento de la interpretación que va de un horizonte a otro. La compenetración pasado-presente exige horizontes abiertos y dinámicos. En virtud del carácter proyectual del Dasein, los horizontes gadamerianos no son autocontenidos ni estáticos. ${ }^{34}$ La comprensión es movimiento de horizontes que se encuentran y fusionan. La fusión se da en el ámbito de la tradición, donde lo viejo y lo nuevo crecen juntos sin distinguirse uno más que el otro. Gadamer aclara que se trata de una fusión de horizontes y no de una integración de dos horizontes en un solo gran horizonte porque ello implicaría hacer caso omiso de la alteridad, es decir, de la tensión texto-pasado-extrañeza / intérpretepresente-familiaridad. ${ }^{35}$ Esta tensión no debe ser eliminada, sino mediada porque es indispensable para el desarrollo del propio ejercicio hermenéutico. En consecuencia, cuando en el proceso comprensivo la conciencia hermenéutica se desplaza hacia horizontes históricos no lo hace hacia mundos totalmente extraños. La tradición ya se ha encargado de vincular el presente con el pasado, de fusionar horizontes. Esta articulación entre familiaridad y extrañeza es posible en la medida que la formación implica un reconocimiento de lo propio en lo extraño. ${ }^{36}$

Lenguaje-comprensión

La tradición tiene para Gadamer un carácter formativo y vinculante que se expresa al interior del lenguaje. A través de la lengua el hombre se posiciona como miembro de una comunidad lingüística, es decir, de una tradición que lo forma. La lengua es continente de formación, es acepción del mundo. Tradición y lenguaje están compenetrados porque entre ambos abarcan todo lo hablado y transmitido en la mediación presente-pasado. La relación con el mundo no puede sustraerse del lenguaje porque la propia existencia del mundo está constituida lingüísticamente. El mundo es, para Gadamer, el suelo común, no hollado por nadie y reconocido por todos quienes hablan entre sí. ${ }^{37}$ Mundo y lenguaje conforman una unidad que da cuerpo, sustenta y acoge al Dasein. ${ }^{38}$

\footnotetext{
32 Ibid., p. 375.

32 Ver ibid., p. 372.

33 Ibid., p. 372.

34 Ibid., p. 375

35 Ibid., pp. 376-377

36 Ibid., p. 43.

37 El autor distingue mundo de entorno. Frente al entorno, es decir, frente al medio en el cual se vive, no se es libre porque existe una relación de dependencia en función de la sobrevivencia y convivencia social. Por el contrario, tener mundo es poder comportarse frente a éste de manera libre. La libertad incluye la formación lingüística del mundo. Para poder elevarse por encima de las coerciones, se debe tener mundo, o para decirlo de otra manera, se debe tener lenguaje. Esto rompe con la noción de un mundo como algo constreñido y limitado lingüísticamente. Ibid., p. 532.

38 Ibid., p. 531.
} 
La relación lingüística con el mundo no es azarosa. La conciencia histórico-efectual realizada en el lenguaje se desenvuelve dentro de un proceso teleológico. El despliegue de las palabras configura una articulación con sentido del mundo, en la cual se ancla y posibilita el aprendizaje de lo formado e interpretado, y de las nuevas experiencias. ${ }^{39} \mathrm{Si}$ la relación con el mundo es lingüística, éste solo es susceptible de ser comprendido porque es Ienguaje. ${ }^{40} \mathrm{En}$ ello deposita Gadamer el carácter de universal que, a su juicio, tiene la hermenéutica. ${ }^{41}$ Por consiguiente, la interpretación es comprensión desde una lingüisticidad hacia otra lingüisticidad. Del lenguaje no se puede salir.

El lenguaje es mediación que permite acceder a aquello que la tradición quiere decir a través del texto. Es piedra angular que posibilita la lógica de pregunta y respuesta indispensable en la comprensióninterpretación. Pero entender también implica aplicar. ${ }^{42} \mathrm{Si}$ el texto no se entiende es porque nada dice al intérprete, es decir, porque no se aplica. Para Gadamer la comprensión del sentido del texto se completa una vez que es aplicado. ${ }^{43}$ La aplicación pasa por la actitud del lector, por la disposición a dejarse decir por el texto. Comprensión implica entonces, aplicación que presupone un vínculo del lector con lo leído. Este involucramiento se distancia del primado del universalismo metodológico que aspira a la mayor neutralidad y objetividad posible. Dado que la aplicación se sostiene en la "historia de los efectos" no es un acto consciente propio de un sujeto autónomo. Aplicar el sentido de un texto quiere decir integrarse al acontecer de la transmisión de la propia tradición donde pasado y presente se encuentran en mediación constante. ${ }^{44}$ Comprender un texto significa traducirlo a la propia situación y escuchar en él la respuesta a las propias preguntas formuladas desde la tradición. Se aplica, se interpreta desde lo ya precomprendido, lo cual motiva a su vez la pregunta.

En definitiva, la aplicación se constituye en la lógica de pregunta y respuesta, es decir, en la estructura y dinámica del diálogo. Un texto solo pasa a ser elocuente gracias a la pregunta que se le haga. ${ }^{45}$ Pregunta, experiencia y apertura son tres conceptos íntimamente relacionados en la hermenéutica gadameriana. La experiencia se basa en el propio preguntar abierto. La pregunta pone en entredicho, cuestiona lo que hasta ese momento forma parte de la experiencia. La pregunta no mantiene ni reproduce lo dado, sino introduce la posibilidad de la diferencia. El preguntar destaca el carácter finito y abierto del Dasein porque lleva a la toma de conciencia de las limitaciones del saber. Aquí radica, según Gadamer, la supremacía hermenéutica de la pregunta que siempre tiene un sentido de orientación que guía la respuesta. Siempre se pregunta desde un horizonte, no es un preguntar vacío. Dado que está inserta en su propio horizonte, la pregunta del texto que pretende comprender desde su historicidad nunca podrá ser reconstruida en su sentido originario. En suma, la hermenéutica de Gadamer no busca el mero revivir, ni la verdad única, sino dar cuenta del sentido de lo interpretado. Cuando se comprende el sentido de la pregunta, se está accediendo a las condiciones históricas, a los presupuestos, la tradición y las verdades que la hicieron posible.

Conforme nos movemos en el lenguaje, preguntando a los textos, el mundo se sigue ampliando, los horizontes se encuentran, dialogan, se fusionan. El movimiento del

39 Gadamer, Hans Georg (1992), “La universalidad del problema hermenéutico” (1966), en Verdad y Método, Tomo II, Ediciones Sígueme, Salamanca, 1992 (pp. 213-224), pp. 222-223.

40 Gadamer, op, cit., p. 567.

41 Gadamer, "La universalidad del problema hermenéutico", op. cit., p. 223.

42 Grondin, J ean (1999), Introducción a la Hermenéutica Filosófica. Editorial Herder, Barcelona, p. 169.

43 El filósofo aspira a que la hermenéutica filosófica aplique así como lo hace la hermenéutica teológica y jurídica. El sentido de lo comprendido: para el jurista interpretar es concretar, aplicar, la ley en cada caso y para el teólogo la concreción tiene lugar en la predicación. Gadamer, Verdad y Método, op. cit., pp. 378-396.

44 Grondin, op. cit., p. 168.

45 Ibid., p. 169. 
espíritu se despoja de sus propósitos y deseos, se aleja de lo conocido y se dirige hacia aquello que en un primer momento puede parecernos extraño. Si el movimiento es completo, si logra el diálogo entre pasado y presente, si articula la particularidad con la totalidad, la comprensión adquiere sentido. Quien interpreta reconoce que ha encontrado en la alteridad elementos comunes. Ir al otro en apertura implica, en definitiva, ir a sí mismo; implica una vuelta a casa, un retorno a lo conocido que lo une al otro. ${ }^{46}$ En suma, este movimiento nos dice que

(...) el horizonte del presente está en un proceso de constante formación en la medida en que estamos obligados a poner a prueba constantemente todos nuestros prejuicios. Parte de esta prueba es el encuentro con el pasado y la comprensión de la tradición de la que nosotros mismos procedemos. El horizonte del presente no se forma pues al margen del pasado. ${ }^{47}$

La realización de esta fusión en la cual hay una toma de conciencia de los prejuicios, de los elementos vinculantes de tradición preexistentes y de los efectos, es la tarea de la conciencia efectual.

Tal como anunciamos en estas frases y como mostraremos a continuación, la relación prejuicio-comprensión ocupa un Iugar privilegiado y determinante en la teoría filosófica gadameriana.

Prejuicio-comprensión

La comprensión es anticipada porque el inicio del movimiento de interpretación tiene que hacer sentido. Quien interpreta se tiene que sentir interpelado, solo así es posible la apertura y la mediación pasado-presente. ${ }^{48}$ Al amparo de este argumento Gadamer utiliza el concepto de "anticipación de la perfección" para decir que solo es comprensible lo que representa una unidad perfecta de sentido. ${ }^{49}$ Sin expectativas la comprensión es vacía. Estas expectativas de sentido se extraen de la relación y contexto precedente, es decir, de aquello que ya ha sido precomprendido y en lo cual el intérprete se ha formado. Dado que la comprensión es movilizada por expectativas, el Dasein se proyecta y reproyecta sucesivamente en el mundo que va comprendiendo, avanzando con ello la penetración de sentido. ${ }^{50} \mathrm{Si}$ el intérprete esperara pasivamente sin anticipar el significado, nada ocurriría. ${ }^{51}$ En suma, se comprende proyectualmente desde la tradición y sus prejuicios. La comprensión no está suj eta al azar, no puede autonomizarse de la preestructura que la subyace, antecede $y$, por lo tanto, condiciona.

La hermenéutica de Gadamer rescata los prejuicios tras el descrédito que sufrieran con la Ilustración. ${ }^{52}$ Los prejuicios anticipan la comprensión:

Los prejuicios no son necesariamente inj ustificadosni erróneos, ni distorsionan la verdad. Lo cierto es que, dada la historicidad de nuestra existencia, los prejuicios en el sentido literal de la palabra constituyen la orientación previa de toda nuestra capacidad de experiencia. Son anticipos de nuestra apertura al mundo, condiciones para que podamos percibir algo, para que eso que nos sale al encuentro nos diga algo. ${ }^{53}$

Sin embargo, el autor recalca que para evitar la degradación del círculo hermenéutico,

46 Weinsheimer, op., cit., p. 70-71.

47 Gadamer, Verdad y Método, op. cit., p. 376

48 Gadamer, "La universalidad del problema hermenéutico", op. cit., p. 218.

49 Gadamer, Verdad y Método, op. cit., p. 363.

50 lbid., p 333.

51 Weinsheimer, op. cit., p. 167

52 Gadamer aclara que el concepto "prejuicio" quiere decir juicio que se forma antes de una convalidación definitiva. Es una predecisión. El prejuicio no tiene en si mismo una connotación negativa, es algo que puede ser valorado positiva o negativamente. Gadamer, Verdad y Método, op. cit. p., 337.

53 Gadamer, "La universalidad del problema hermenéutico", op. cit., p. 218. 
la tarea primera del intérprete es no dejarse llevar por sus ocurrencias propias ni por los prejuicios para así poder orientar la mirada hacia la cosa. ${ }^{54}$ Así como la interpelación de sentido es condición hermenéutica suprema, la suspensión del prejuicio es su exigencia. ${ }^{55}$ Los prejuicios no deben eliminarse, ni sustituirse porque desde ellos se comprende. Eliminarlos implicaría no reconocer a la tradición como contenedora de la comprensión y caer en la ingenuidad del objetivismo histórico que olvida la propia historicidad. Se los debe poner en entredicho para abrirse a lo novedoso del texto. En otras palabras, hay que ser consciente de ellos y controlarlos, lo que implica poner en suspenso su validez. Esto es posible cuando el prej uicio es "estimulado" por su encuentro con la tradición a través de la lógica de pregunta y respuesta. Al preguntar al texto el intérprete se abre a las posibilidades, a las respuestas, a las verdades. No podría hacerlo si no controlara a sus anticipaciones.

La "historia de los efectos" nos dice que son infinitas las posibles interpretaciones de una misma obra, pero que cada comprensión es histórica porque está ligada a la finitud de la existencia humana y del conocimiento. El Dasein que comprende se abre al mundo desde un horizonte que contiene determinados prejuicios. ${ }^{56}$ Más que ningún otro elemento en su teoría, el prejuicio indica el carácter finito y la historicidad de la comprensión. Este aspecto no es considerado por los neokantianos, para quienes la orientación a las ciencias presupone la no situacionalidad y la no historicidad del sujeto trascendental. Ni siquiera el historicismo, pese a reafirmar la historicidad y relativismo de cada expresión humana, reconoce la propia historicidad del intérprete. Aun cuando estas corrientes filosóficas son distintas tienen en común el pensar en una conciencia neutralizada, libre de prejuicios como única forma de conocer.

El prejuicio se desarrolla al margen de la conciencia. No solo es previo al sujeto trascendental, sino límite a su pretendida infinitud. ${ }^{57}$ Los prejuicios no se adquieren a través de un acto reflexivo, vienen dados por el proceso de formación; están inscritos en la tradición y son una de las expresiones más acabadas del carácter arrojado que tiene la existencia humana. En virtud del prejuicio, comprendemos el mundo antes de tener un vínculo reflexivo con él. Los prejuicios son en sí mismos realidad histórica entendida como proceso en constante formación e interpretación. Bajo esta perspectiva hermenéutica nunca se da inicio a algo, siempre se está al interior de un proceso en marcha, siempre se está arrojado en el mundo. En consecuencia, ningún método puede ser fundacional ni obviar los prejuicios porque quien comprende y lo comprendido siempre están arrojados en el mundo. ${ }^{58}$ Lo anterior reafirma la circularidad de la hermenéutica y su resistencia al universalismo metodológico.

\section{Consideraciones Finales}

La relación de la tradición -formativa, lingüística y prejuiciosa- con la autoridad tiene importantes implicancias para la interpretación histórica. Lo anterior cobra especial realce si se considera el papel que da Gadamer a la tradición en tanto fuente de verdad. Verdad entendida como historicidad, como algo que acontece en el encuentro entre el texto y el intérprete mediado por la tradición y que se sustrae, por lo tanto, a todo método científico que pretenda supeditarla a la lógica de sus procedimientos. ${ }^{59}$

54 Gadamer, Verdad y Método, op. cit., pp. 331-333.

55 Ibid., p. 369.

56 Nicholson, Graeme, "Truth in metaphysics and in hermeneutics" (pp. 309-319), en Edwin, op. cit., p. 317.

57 Linge, op. cit., pp. XV y XVII.

58 Weinsheimer, op. cit. pp. 10-11.

59 La articulación entre los conceptos de tradición y verdad es compleja y profunda y ocupa parte importante de la reflexión del autor. Pero no es el momento de entrar a discutir el concepto de verdad en Gadamer, el cual tampoco es claramente definido en Verdad y Método aún cuando el autor destaca tres contextos de verdad que se sustraen del universalismo metodológico, a saber, el arte, la historia y la filosofía y que forman, por consiguiente, su núcleo de interés. Gadamer, Verdad y Método, op. cit., "Introducción". 
El autor sostiene que cuando se comprende la tradición, no solo se comprenden textos, sino se adquieren perspectivas y se conocen verdades. ${ }^{60}$

La experiencia de la tradición histórica va fundamentalmente más allá de lo que en ella es investigable. Ella no es solo verdad o no verdad en el sentido en el que decide la crítica histórica; ella proporciona siempre verdad, una verdad en la que hay que participar. ${ }^{61}$

A la luz de estas palabras se puede hablar de la verdad como momento al interior de la historia efectual, de verdad como algo propio, no ajeno, como algo a lo cual se pertenece. La verdad no se va a buscar al pasado, sino surge de la mediación entre el pasado y el presente. Mediación que se suscita cada vez que alguien busca interpretar la voz de la tradición. Hay tantas interpretaciones como mediaciones haya. Así, nunca se puede hablar de una interpretación que agote el texto. Solo se puede hablar de interpretaciones. Tras cada uno de estos movimientos surgen verdades. Verdades, no verdad única. En la hermenéutica gadameriana las verdades no son absolutas, eternas, ni finales. No podría ser de otra manera porque derivan de una tradición que en su esencia es abierta y dialógica. Por consiguiente, la verdad gadameriana no es impositiva ni totalizadora. Por el contrario, que la verdad se desprenda de la tradición le da su carácter finito, contingente, histórico. Sin embargo, creemos que esta noción de verdad puede perderse 0 al menos desperfilarse dada la relación constitutiva entre tradición y autoridad que el propio autor propone.

Para analizar este tema es preciso volver sobre el tema de los prejuicios. Éstos definen una orientación, sin ellos no es posible comprender. ¿Son correctos los prejuicios en cuestión? y ¿cuál es su origen y validez?, son dos preguntas abordadas por Gadamer, pero que dejan un conjunto de interrogantes y temas no resueltos.

La no percepción de los propios prejuicios, es decir, la ausencia de conciencia, impide que la comprensión alcance su verdadera posibilidad porque lleva a la arbitrariedad. Según el autor, la objetividad de la comprensión radica en la confirmación de las opiniones previas, mientras las opiniones inadecuadas se van aniquilando en el propio proceso. ${ }^{62}$ Pero ies posible distinguir los prejuicios correctos o adecuados de las opiniones previas falsas que pueden llevar a malentendidos? El gran problema es cómo asegurar que los prejuicios sean los adecuados -a la cosa- sobre todo si se considera que mientras están determinando al intérprete éste no es consciente de ellos. Gadamer responde a esta interrogante apelando a la distancia en el tiempo, la cual no debe ser superada, sino considerada hermenéuticamente. Ello garantiza la adecuación de los prej uicios porque da patrones seguros de juicio. ${ }^{63}$ Solo el tiempo permite hablar de prejuicios controlables porque lo actual presenta presupuestos demasiados fuertes para poder conocerlos. La extinción de los nexos actuales hace posible la comprensión; solo se puede conocer desde una distancia histórica. Pero que la distancia garantice una comprensión adecuada no quiere decir que la agote.

Sin embargo, desde nuestra opinión, la distancia en el tiempo como criterio que asegura la adecuación de los prejuicios es cuestionable. ¿Cuánta distancia -si es posible hablar así- se requiere o es suficiente para ser consciente de los propios prejuicios? Desde la óptica gadameriana en tanto intérpretes somos parte del torrente de la "historia de los efectos" de una obra determinada, por lo cual la conciencia que se pueda tener es efectuada. Nos parece que la conciencia efectual no es capaz de evaluar la distancia en la que ella misma se mueve. J ustamente, para

60 Ibid., p. 23.

61 Ibid., p. 25.

62 libid., pp. 333-334.

63 Citado en Grondin, op. cit., p. 164. 
Gadamer lo que caracteriza a la conciencia efectual es que a diferencia de la conciencia histórica reflexiva no puede y no debe salirse del círculo hermenéutico. Por consiguiente, frente al problema que estamos planteando, probablemente Gadamer diría que el rol de la conciencia hermenéutica no es evaluar la distancia, sino experimentarla como mediación. Desde nuestro punto de vista, el problema de este argumento es que finalmente solo se puede saber si los prejuicios fueron los adecuados a partir de sus propios efectos, es decir, a partir de lo que otros posteriormente interpreten de dicha interpretación. A nuestro entender, no se trataría, entonces, ni de una conciencia operando a priori, ni durante, sino a posteriori. Si los prejuicios son adecuados o no, quedaría como pregunta pendiente para el propio intérprete. Más aún, el autor ha sido criticado por caer en una circularidad tautológica que finalmente no puede dar cuenta de la adecuación: son correctos Ios prejuicios que llevan a interpretaciones verdaderas, y son verdaderas las interpretaciones que se desprenden de prejuicios verdaderos. ${ }^{64}$ El círculo, valga la redundancia, se cierra en sí mismo, de allí no se puede salir, por lo tanto, no resulta posible evaluar la distancia a la distancia.

En lo que respecta a la legitimidad de los prejuicios, la pregunta por su origen y validez lleva al tema de la autoridad. Podríamos pensar que los prej uicios son válidos y legítimos porque han resistido la sanción de la historia o de la tradición a lo largo del tiempo, con lo cual se le daría a la tradición un carácter de autoridad por ser perdurable. ${ }^{65}$ Si bien para Gadamer la autoridad es efectivamente un tipo de tradición, su concepto de autoridad trasciende la mera perdurabilidad.

Lo consagrado por la tradición y por el pasado posee una autoridad que se ha hecho anónima, y nuestro ser histórico y finito está determinado por el hecho de que la autoridad de lo transmitido, y no solo lo que se acepta razonadamente, tiene poder sobre nuestra acción y sobre nuestro comportamiento (...) La realidad de las costumbres es y sigue siendo ampliamente algo válido por la tradición y la procedencia. Las costumbres se adoptan libremente, pero ni se crean por libre determinación ni su validez se fundamenta en esta. Precisamente es esto lo que Ilamamos tradición: el fundamento de su validez. ${ }^{66}$

Ahora bien, la autoridad es fuente de prejuicios tanto para la Ilustración como para Gadamer. Pero mientras para el primero tiene una connotación negativa, para el segundo es positiva. Negativa porque así como la precipitación es fuente de equivocación que induce a error, la autoridad es la culpable de que no se emplee la razón. Para el mundo ilustrado, autoridad y razón son excluyentes. El uso metódico de la razón es suficiente para proteger de error. Por lo tanto, la autoridad -cargada de prejuicios- impide el uso de la razón, lleva necesariamente a error. La autoridad no puede sino supeditarse a la razón. ${ }^{67}$ Positiva porque siendo fuente de prejuicios, para Gadamer la autoridad puede ser también fuente de verdad, aspecto no considerado por la Ilustración. Y puede ser fuente de verdad porque la autoridad gadameriana, en tanto tradición, no tiene un carácter coercitivo, sino productivo y racional. Autoridad y razón no son antagónicas en la hermenéutica de Gadamer, de la misma manera que tradición y razón tampoco lo son. El problema para el autor es que el concepto de autoridad ha sido malentendido y deformado porque la Ilustración lo contrapuso al concepto de razón y de libertad.

64 Nicholson, op. cit., p. 318.

65 Aguilar Rivero, Mariflor 1998. Confrontación, crítica y hermenéutica. Gadamer, Ricoeur, Habermas, Distribuciones Fontamara, México, 1998, pp. 139 y 191.

66 Gadamer, Verdad y Método, op. cit., p. 348.

67 Ibid., p. 346. 
Bajo el contexto ilustrado la autoridad es pura obediencia ciega. ${ }^{68}$ Para el autor en cambio la esencia de la autoridad reside en presuponer que el otro puede tener una mejor percepción, un conocimiento superior que rebasa el propio. ${ }^{69}$ La autoridad es un atributo personal, pero no se reduce a ello. Supone la obediencia, pero no como mero acto de sumisión y de abdicación de la razón, sino como acto de reconocimiento al conocimiento. Por este motivo ha adquirido autoridad. Tal reconocimiento es un acto libre en el cual la razón se hace cargo de sus propios límites y le atribuye al otro una perspectiva más acertada. Por consiguiente, lo que dice la autoridad no puede ser ni irracional ni arbitrario. En este escenario, todo prejuicio anclado en ella es legítimo, es decir, tiene validez como orientador de la comprensión. ${ }^{70}$

La rehabilitación del prejuicio, de la tradición y, con ello, de la autoridad tiene importantes consecuencias para la interpretación histórica. Consideramos que darle a la autoridad el criterio de legitimidad para discriminar los prejuicios adecuados de los inadecuados puede ser riesgoso. Queda en manos de la autoridad definir lo que es una buena o verdadera interpretación de una mala o falsa. Lo peligroso es que en la perspectiva gadameriana la autoridad es autocontenida. Autoridad es tradición, por eso es legítima. Las cosas andan bien, es decir, las interpretaciones múltiples y diversas se suceden unas a otras mientras la tradición siga manteniendo su carácter dialógico y abierto. El problema se suscita cuando la tradición se cierra. ¿Por qué podría ocurrir esto? Porque lo que emana de la autoridad es poder. Detrás del poder hay siempre intereses. La autoridad es poder estabilizado; la autoridad se puede comprender como una especie del género "poder" o como fuente de poder. ${ }^{71}$ Es difícil separar autoridad de poder, entendiendo el poder como la capacidad de hacer que otro haga cosas aún contra su voluntad. El poder se cierra sobre sí mismo, delimitando sus fronteras para evitar fugas y entradas intrusas. Quien tiene el poder difícilmente lo comparte. Quien tiene el poder lo conserva. Bajo este planteamiento, al poder le es mucho más conveniente una concepción de tradición como mera perdurabilidad que como apertura dialógica. Cuando hay intereses de por medio, la concepción gadameriana de la tradición y el reconocimiento al conocimiento como sustento último de la autoridad se desperfilan. ¿Quién tiene poder, suspende real y necesariamente sus prejuicios, está en una actitud de apertura? No, porque cuando hay poder involucrado los prejuicios se confunden con los intereses los que difícilmente los intereses son suspendidos para su examen. Bajo la impronta del poder, la tradición y con ello la autoridad corren el riesgo de cerrarse, de no permitir más diálogo. La apertura puede pasar de ser un elemento constitutivo e ineludible de la tradición a uno amenazante. La autoridad llevada al límite puede terminar por evitar y anular el diálogo. El problema es que no tiene contraparte porque ella misma encarna lo que la historia ha sido, ella misma es la realización de los efectos. Bajo la óptica ilustrada la razón es la contraparte a la autoridad; la razón limita la autoridad. Pero en la hermenéutica gadameriana la razón es aliada de la tradición y de la autoridad. En este contexto, son pertinentes las posturas críticas a Gadamer, las cuales plantean que la tradición sostiene una autoridad que difícilmente se puede desafiar ${ }^{72}$ y toda interpretación también está sujeta a la tradición y a la presión de la autoridad. ${ }^{73}$

La întima relación tradición-autoridad no puede sino arrojar un sinnúmero de preguntas. ¿Cómo limitar la autoridad cuando comete excesos en virtud del poder que dispone? ¿Cómo saber y cómo dar cuenta de esos excesos si se comparte con ella todo lo

68 Ibid. p. 347.

69 Gadamer, Hans Georg, “La verdad en Ias ciencias del espíritu” (1955), en Verdad y Método. Tomo II, Ediciones Sígueme, Salamanca, 1992 (pp. 43-49), p. 45.

70 Gadamer, Verdad y Método, op. cit., pp. 347-348.

71 Bobbio, Norberto; Mattencia, Nicola; y Pasquino, Gianfranco (1983) Diccionario de Política. Tomo I, Siglo XXI Editores, México, p. 118.

72 Eagleton, Terry (1985), Literary Theory. An Introduction, Basil Blackwell, Oxford, (first published in 1983), pp. 72-73.

73 Nicholson, op. cit., p. 317. 
acontecido, si se es parte de la misma "historia de los efectos"? ¿Qué ocurre si la distancia temporal como criterio para asegurar la adecuación de los prejuicios está "controlada" por la autoridad una vez que la tradición "se ha cerrado"? ¿Cómo criticar la autoridad si no se puede salir de la tradición? En los años posteriores a la publicación de Verdad y Método, especialmente en los años 70, este tipo de interrogantes provocó una ardua polémica entre la hermenéutica de Gadamer y sus detractores. ${ }^{74}$

Asumir que las verdades se desprenden de la tradición-autoridad es riesgoso porque finalmente las verdades no están legitimadas necesariamente por quien sabe más como lo quisiera Gadamer, sino por quien tiene más poder. Al interior de mundo historiográfico esto no tiene un impacto menor. Sus implicancias pueden ser enormes. Las autoridades historiográficas pueden autopercibirse como las articuladoras indiscutibles de las interpretaciones correctas y verdaderas. La tradición, no ya la tradición gadameriana, sino la que "fue cerrada por el poder", por decirlo de alguna manera, las avalúa como legítimas interpretadoras. Si la tradición se cierra, nos parece que las verdades corren el riesgo de absolutizarse o al menos de tender a ello al interior de un círculo vicioso: la autoridad establece cuál es la interpretación verdadera; y la autoridad está en lo cierto porque se sustenta en la interpretación verdadera. Es aquí cuando la tradición puede convertirse en institución interpretadora y pasar a establecer, entonces, "verdades históricas", estáticas y definitivas. Esto es lo que Gadamer rechaza por principio, pero es al punto al cual puede llegar si sus argumentos se llevan al límite. Pese al valor y aporte indiscutibles de Verdad y Método esta es, a nuestro juicio, una de las principales consecuencias no previstas, ni deseadas, uno de los principales peligros de la tríada gadameriana tradición-autoridadverdad.

\section{BIBLIOGRAFÍA}

ABBAGNANO, NICOLA (1966), Diccionario de filosofía, Fondo de Cultura Económico, Segunda edición en español, México.

AGUILAR RIVERO, MARIFLOR (1998), Confrontación, crítica y hermenéutica, Distribuciones Fontamara, México.

BOBBIO, NORBERTO; MATTENCIA, NICOLA; Y PASQUINO, GIANFRANCO (1983), Diccionario de Política, Tomo I, Siglo XXI Editores, México.

BURNS, GERALD L. (1992), Hermeneutics Ancient and Modern, Yale University Press, Michigan.

CORETH, EMERICH (1972), Cuestiones fundamentales de hermenéutica, Editorial Herder, Barcelona.

EAGLETON, TERRy (1985), Literary Theory. An Introduction, Basil Blackwell, Oxford, 1985 (first published in 1983).

FERRATER, JOSÉ (1988), Diccionario de filosofía, Tomo 4, Alianza Editorial, Sexta reimprensión, España.

GADAMER, HANS GEORG (1992), "La universalidad del problema hermenéutico" (1966), en Verdad y Método, Tomo II, Ediciones Sígueme, Salamanca (pp. 213-224).

74 Por lo fructífera y extendida de la discusión en los años 60 y 70's vale mencionar la figura de J ürgen Habermas (1929), exponente central de la Teoría Crítica, heredera -desilusionada- de la Escuela de Frankfurt. Por problemas de tiempo y espacio, y porque rebasa los obj etivos de este trabaj 0 , no incluiremos la crítica habermaseana, pero destacaremos dos aspectos centrales que abren las puertas a reflexiones futuras: la existencia de comunicación distorsionada y la posibilidad de desarrollar una actitud crítica frente a la tradición. Lo primero critica la postura del lenguaje como algo siempre honesto, transparente y verdadero. Habermas no cree en el lenguaje como fiel y desinteresado mediador hermenéutico. Los intereses detrás del poder tiñen el lenguaje y lo instrumentalizan a su favor. Lo segundo lleva implícita la apuesta a algo mejor. Frente al primado de la tradición Habermas opone la necesidad de la emancipación que no opera sino distanciándose de la tradición en virtud de la razón. Al igual que Gadamer, Habermas asume que la comprensión está estructuralmente sumergida en tradiciones, pero ello no quiere decir que no se pueda tomar distancia frente a ellas, ni que la reflexión no pueda modificarlas. Mientras Gadamer reacciona contra la Ilustración, Habermas va a su rescate. Aguilar, op. cit. 


\section{Revista CUHSO volumen 13 no 1}

..... (1992), "La verdad en las ciencias del espíritu" (1955), en Verdad y Método, Tomo II, Ediciones Sígueme, Salamanca (pp. 43-49).

(1997), "Reflections on my Philosophical J ourney" (pp. 3-57), en Edwin, Lewis. The Philosophy of Hans Georg Gadamer, Chicago and La Salle, USA.

...... (1997), Verdad y Método, Tomo I, Ediciones Sígueme, Séptima Edición, Salamanca, 1997.

GRONDIN, JEAN (1999), Introducción a la Hermenéutica Filosófica, Editorial Herder, Barcelona.

LINGE, DAVID. (ed.) (1977), “Editor's Introduction", en Gadamer, Hans Georg. Philosophical Hermeneutics, University of California Press, USA.

NICHOLSON, GRAEME (1997), "Truth in Metaphysics and in Hermeneutics", en Edwin, Lewis, The Philosophy of Hans Georg Gadamer, Chicago and La Salle, USA, (pp. 309-319).

REALE, GIOVANNI Y ANTISERI, DARÍO (1988), Historia del pensamiento fil osófico y científico, Tomo Tercero, Editorial Herder, Barcelona.

VATTIMO, GIANNI (1992), Ética de la interpretación, Ediciones Paidós, Argentina, 1992.

WEINSHEIMER, J OEL C. (1985), Gadamer's Hermeneutics: a Reading of Truth and Method, Yale University Press, New York. 